\title{
A single hydrophobic cleft in the Escherichia coli processivity clamp is sufficient to support cell viability and DNA damage-induced mutagenesis in vivo
}

Mark D Sutton $^{1 *}$, Jill M Duzen ${ }^{2,3}$, Sarah K Scouten Ponticelli ${ }^{2}$

\begin{abstract}
Background: The ubiquitous family of DnaN sliding processivity clamp proteins plays essential roles in DNA replication, DNA repair, and cell cycle progression, in part by managing the actions of the different proteins involved in these processes. Interactions of the homodimeric Escherichia coli $\beta$ clamp with its known partners involves multiple surfaces, including a hydrophobic cleft located near the C-terminus of each clamp protomer.

Results: A mutant $E$. coli $\beta$ clamp protein lacking a functional hydrophobic cleft $\left(\beta^{C}\right)$ complemented the temperature sensitive growth phenotype of a strain bearing the dnaN159 allele, which encodes a thermolabile mutant clamp protein $(\beta 159)$. Complementation was conferred by a $\beta^{C} / \beta 159$ heterodimer, and was observed only in the absence of the dinB gene, which encodes DNA polymerase IV (Pol IV). Furthermore, the complemented strain was proficient for umuDC (Pol V) -dependent ultraviolet light (UV) -induced mutagenesis.

Conclusions: Our results suggest that a single cleft in the homodimeric E. coli $\beta$ sliding clamp protein is sufficient to support both cell viability, as well as Pol III, Pol IV, and Pol V function in vivo. These findings provide further support for a model in which different Pols switch places with each other on DNA using a single cleft in the clamp.
\end{abstract}

\section{Background}

Viability of all organisms depends upon a capacity to both accurately repair damaged DNA, as well as tolerate DNA lesions that for whatever reason evade repair [1]. In contrast to repair, which acts to either directly reverse the damage, or to excise modified bases so that the affected sequence may be re-synthesized, DNA damage tolerance mechanisms act to enable replication past the damaged site, without catalyzing repair of the lesion(s). Generally speaking, DNA damage tolerance mechanisms fall into one of two broad classes: (i) daughter strand switching, which refers to a collection of recombinational mechanisms that act to physically

\footnotetext{
* Correspondence: mdsutton@buffalo.edu

'Department of Biochemistry, and Witebsky Center for Microbial

Pathogenesis and Immunology, School of Medicine and Biomedical Sciences, University at Buffalo, State University of New York, 3435 Main

Street, 140 Farber Hall, Buffalo, NY 14214, USA

Full list of author information is available at the end of the article
}

restructure the DNA at the replication fork to enable the complementary daughter strand to act as template to support replication beyond the damaged site(s) [1,2]; and (ii) translesion DNA synthesis (TLS), which refers to the process by which one or more specialized DNA polymerases (Pols) are recruited to catalyze replication past damaged sites in the DNA [3]. Since most Pols capable of catalyzing TLS display remarkably low fidelity on undamaged DNA, their actions must be very tightly controlled in vivo to guard against unwanted mutations $[4,5]$. Although multiple mechanisms likely contribute to the coordinate regulation of replicative and TLS Pols, considerable effort over the past decade has been devoted to understanding the roles played in this process by the ubiquitous family of DnaN sliding clamp proteins $[5,6]$.

Bacterial sliding clamps, termed $\beta$ or DnaN, are encoded by the dnaN gene, and function as homodimers. Like their eukaryotic counterparts, these clamps 
are loaded onto DNA in an ATP-dependent manner by a multi-subunit clamp loader complex [7]. Once loaded, they recruit the replicative Pol (Pol III), as well as other partner proteins involved in various aspects of DNA replication, repair, and damage tolerance [5]. E. coli $\beta$ clamp, like other DnaN family members, contains a hydrophobic cleft positioned near the C-terminus of each protomer that interacts competitively with a conserved clamp-binding motif (CBM) sequence present in most, if not all partners (see Figure 1 \&2; [8]). Since the $\beta$ clamp functions as a homodimer, it contains two such clefts, suggesting it may simultaneously manage the actions of two different partner proteins on DNA by acting as a molecular 'toolbelt.' In this model, each partner is bound to a different cleft in the clamp (see Figure 1A; [9-11]). Consistent with this model, a single cleft in the clamp is sufficient to support assembly of the clamp onto DNA, as well as processive replication by the replicative E. coli Pol (Pol III) using an in vitro system reconstituted with purified components, suggesting the other cleft is available for physical interaction with a second partner protein $[12,13]$.

Although the CBM-clamp cleft interaction is essential for biological function of all known clamp partners examined to date, it is becoming increasingly evident that partners make functionally important contacts with non-cleft surfaces of the clamp as well (reviewed in [5]). For example, residues E93 and L98 of the clamp, which are located on the rim, interact with TLS Pols IV and V (see Figure 2C; [13-16]). Using a heterodimeric clamp protein $\left(\beta^{\mathrm{C}} / \beta^{+}\right)$bearing a mutant protomer lacking a functional cleft $\left(\beta^{C}\right)$ in complex with a

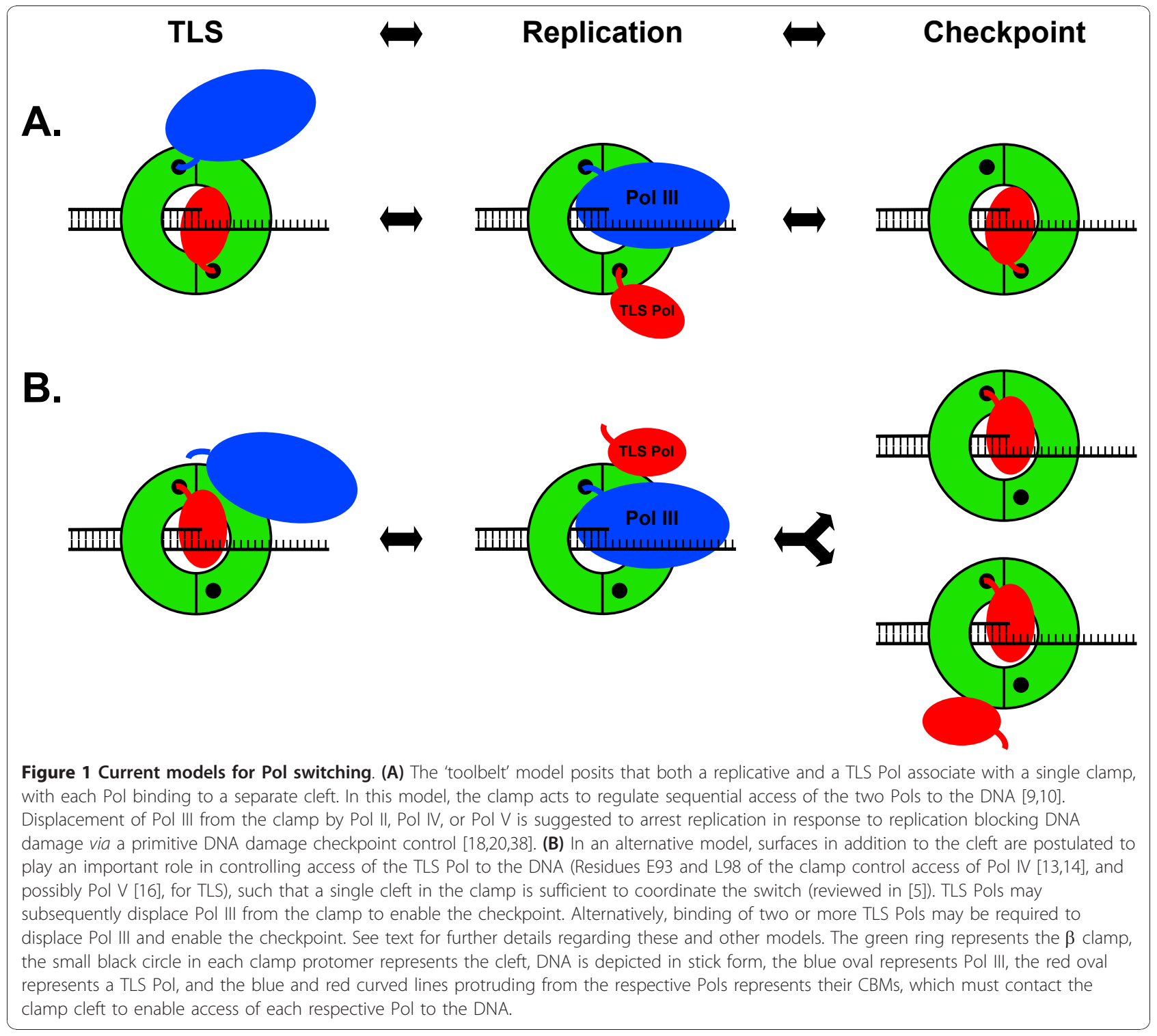




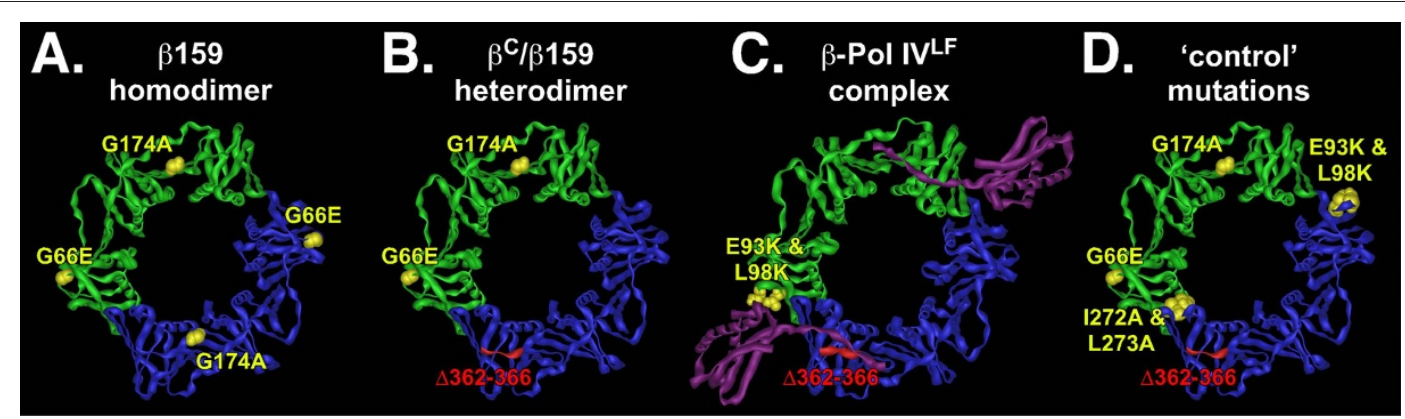

Figure 2 Sliding clamp mutations utilized in this study. (A) Positions of mutations present in $\beta 159$ (G66E and G174A) are represented as yellow space filled atoms on the structure of the wild-type clamp. (B) Proposed structure of the $\beta^{C} / \beta 159$ heterodimer. Positions of G66E and G174A substitutions in $\beta 159$ are represented as yellow space filled atoms, while residues 362-366, which are deleted from $\beta^{C}$, are colored red. (C) Structure of the Pol IV little finger (Pol IV ${ }^{L F}$ ) domain in complex with the $\beta$ clamp as reported by Bunting et al. [14]. Pol IV ${ }^{L F}$ is in purple. Pol IVLF contacts residues E93 and L98, as well as 362-366 of the clamp; position of E93K and L98K substitutions (yellow), and $\triangle 362-366$ (red) are indicated. (D) Positions of the E93K-L98K and I272A-L273A mutations used to characterize the ability of $\beta^{C}$ to complement the temperature sensitive growth phenotype of the dnaN159 strain are shown on the presumed structure of the $\beta^{C} / \beta 159$ heterodimer, which bears the G66E, G174A, and $\triangle 362-366$ mutations. Figures were generated using Imol, and the coordinates for either the wild-type clamp (2POL), or the $\beta$ clampPol IV little finger complex (1UNN) obtained from the PDB.

wild-type protomer $\left(\beta^{+}\right)$, we recently determined that a single cleft, together with the adjacent rim contact were both required for Pol IV to switch with a stalled Pol III in vitro (see Figure 1B; [13]). These results suggest a single clamp may utilize a combination of cleft and non-cleft surfaces to simultaneously manage the actions of more than two partners on DNA $[5,13]$.

Besides their roles in TLS, Pols IV and V additionally act in a primitive DNA damage checkpoint control [17-19]. Pol II is also suggested to act in a checkpoint [19]. Interactions of these Pols with components of the replication machinery, particularly the $\beta$ clamp, are suggested to slow or even arrest DNA replication following replication blocking damage to allow time for accurate repair (see Figure 1; [18-20]). However, the mechanistic relationship between the proposed checkpoint and Pol switching is presently unknown.

In addition to its protein partners, the clamp also interacts with the DNA template that it encircles $[21,22]$. Clamp-DNA interactions involve the cleft, as well as two additional clamp surfaces, one of which (residues H148-R152) also interacts with both Pol II and Pol IV [21]. Taken together, these results suggest that the clamp may play a direct role in physically sensing damaged DNA, and upon doing so, alter the way in which it interacts with the DNA template to enable recruitment of one or more DNA repair proteins, and/ or specialized Pols to enable a series of concerted switches designed to coordinate replication with DNA repair and TLS [21].

Our current appreciation of clamp functionality is based largely on results of in vitro biochemical assays (reviewed in $[5,7,23])$. For example, recent in vitro experiments exploiting heterodimeric clamps comprised of two distinct $\beta$ protomers revealed that a single cleft of the clamp was both necessary and sufficient for supporting a switch between Pol IV and a stalled Pol III $[5,12,13]$. However, many questions concerning the biological significance of this as well as other current models remains largely untested, due to the lack of a method for analyzing defined heterodimeric clamp proteins in vivo. As part of an effort to address this deficiency, we engineered a synthetic dnaN gene expressing tandem clamp protomers fused head-to-tail by a short amino acid linker bearing a $\mathrm{His}_{6}$ tag. Based on Western blot analysis using both antibeta clamp and anti-Penta.His (Qiagen) antibodies, the linker sequence was susceptible to a significant level of proteolysis in vivo (J.M. Duzen and M.D. Sutton, unpublished results). We therefore pursued a separate strategy that exploited an inactive, mutant form of the $\beta$ clamp lacking a functional cleft $\left(\beta^{\mathrm{C}}\right)$ that we determined to be capable of complementing the temperature sensitive growth phenotype of the dnaN159 strain to provide a defined population of $\beta^{\mathrm{C}} / \beta 159$ heterodimeric clamp protein for genetic analysis. Using this system, we tested several critical predictions of the models discussed above and summarized in Figure 1. Our findings, discussed below, suggest that a single cleft in the $E$. coli $\beta$ clamp protein is sufficient to support cell viability, as well as manage the actions of Pols III, IV, and V during DNA replication and TLS in vivo.

\section{Results \& Discussion}

$\beta^{C}$ complements the temperature sensitive growth phenotype of the dnaN159 strain provided that Pol IV is inactivated

$\beta^{\mathrm{C}}$ lacks a functional cleft due to deletion of the C-terminal five residues (see Figure 2), rendering it 
completely inactive for loading onto DNA, as well as for supporting Pol III replication [12]. In stark contrast, a heterodimeric form of the clamp bearing a recombinant $\beta^{C}$ protomer in complex with a wild-type protomer $\left(\beta^{C} /\right.$ $\beta^{+}$) was recently determined to be indistinguishable from the wild-type clamp with respect to its ability to be loaded onto primed DNA, and stimulate processive DNA synthesis by Pol III in vitro $[12,13]$. The $\beta^{C} / \beta^{+}$ heterodimer was also comparable to the wild-type clamp with respect to coordinating a switch between Pol IV and a stalled Pol III in vitro [13]. Based on these findings, we hypothesized that if a clamp bearing a single cleft was competent for supporting E. coli viability, then $\beta^{C}$ might complement the temperature sensitive growth phenotype of the dnaN159 strain via formation of a functional $\beta^{\mathrm{C}} / \beta 159$ heterodimeric clamp protein in vivo (see Figure 2B). The dnaN159 allele expresses a mutant clamp bearing G66E and G174A substitutions ( $\beta 159$; see Figure 2$)$, and strains bearing this allele are unable to grow at temperatures above $37^{\circ} \mathrm{C}$ [24]. Of importance to the work discussed herein, $\beta 159$ does not undergo detectable proteolysis during incubation at elevated temperatures (see Figure 3; [24-26]), and was capable of forming heterodimers with either the wild-type or a mutant $\beta$ clamp protein bearing alanine substitutions of residues 148-152 in vivo [21].

We initiated these studies by first asking whether physiological levels of the wild-type, $\beta 159$, or $\beta^{C}$ clamp proteins, when expressed separately from a low-copynumber plasmid (Figure 3), were capable of complementing the temperature sensitive growth phenotype of the dnaN159 strain. Consistent with previous reports $[26,27]$, strain MS101 bearing either the empty plasmid control (pWSK29), or the $\beta 159$-expressing plasmid (pJD109), grew at $30^{\circ} \mathrm{C}$, but not at $42^{\circ} \mathrm{C}$ (Figure 4). In contrast, this same strain containing a plasmid expressing the wild-type clamp (pJD100) grew equally well at

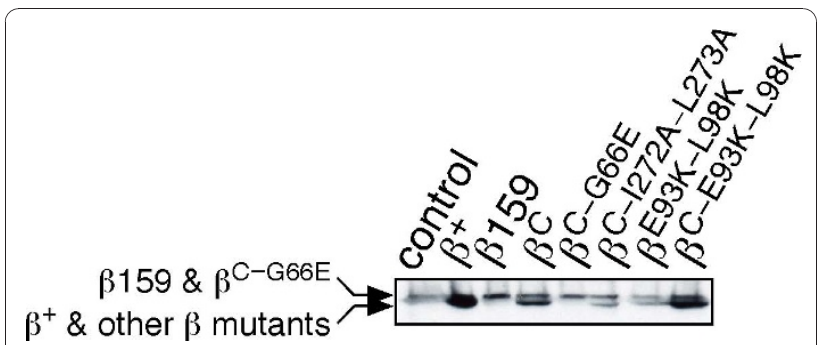

Figure 3 Steady-state levels of mutant $\beta$ clamp proteins. Steady-state levels of the different clamp proteins were examined as described in 'METHODS.' As noted in 'METHODS,' we previously determined the number of clamp proteins expressed in E. coli MS101 bearing either pWSK29, or pWSK29-derived plasmids expressing different clamp proteins [27]. Note that both $\beta 159$ and $\beta^{\mathrm{C}-\mathrm{G} 66 \mathrm{E}}$ possess altered mobility in SDS-PAGE relative to the wildtype clamp, or the other mutants, due to the G66E substitution [24].

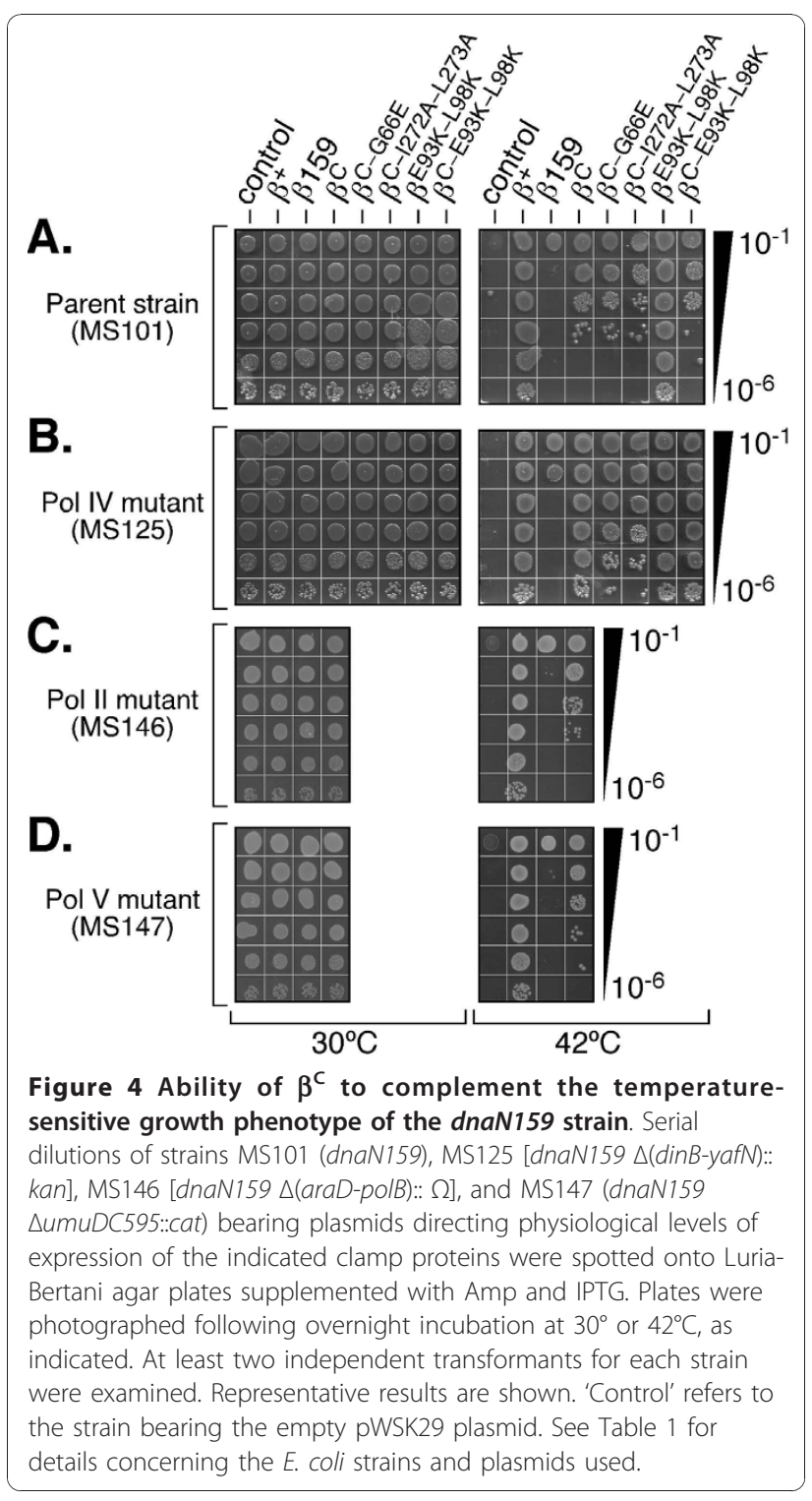

both $30^{\circ}$ and $42^{\circ} \mathrm{C}$, indicating that $\beta^{+}$fully complemented the temperature sensitivity of the dnaN159 strain. Despite the fact that a single cleft in the clamp was sufficient for supporting both clamp loading as well as Pol III function in vitro [12], $\beta^{C}$ was unable to complement temperature sensitivity of the dnaN159 strain (Figure 4). Based on Western blotting, $\beta^{C}$ was expressed at physiological levels (Figure 3), implying that its inability to complement the dnaN159 strain was due to a functional defect.

We have previously described circumstances under which Pol II, Pol IV and/or Pol V are capable of interfering with viability of the dnaN159 strain [21,24,26,28,29]. In light of these findings, we hypothesized that the inability of $\beta^{\mathrm{C}}$ to complement the dnaN159 strain may be due to the action of one or more specialized Pols. In order to 
distinguish between a model in which the inability of $\beta^{C}$ to complement temperature sensitive growth of the dnaN159 strain was attributable to a requirement of both clamp clefts for $E$. coli viability, and a model in which a single cleft in the clamp is sufficient to support viability, but one or more TLS Pols was acting to impair function of the $\beta^{\mathrm{C}} / \beta 159$ heterodimer at $42^{\circ} \mathrm{C}$, we asked whether $\beta^{\mathrm{C}}$ could support temperature resistant growth of a dnaN159 strain lacking either Pol II [ $\Delta(\operatorname{araD}-p o l B):: \Omega]$, Pol IV $[\Delta(\operatorname{din} B-y a f N):: k a n]$, or Pol V $(\Delta u m u D C 596::$ ermGT) function. As shown in Figure $4 \beta^{C}$ was able to fully complement temperature sensitive growth of the dnaN159 strain lacking Pol IV function [ $\Delta(\operatorname{din} B-y a f N)::$ $k a n]$. In contrast, $\beta^{C}$ was unable to complement growth of the dnaN159 strain lacking Pol II (MS146) or Pol V (MS147). Thus, Pol IV may outcompete Pol III for interaction with the $\beta^{C} / \beta 159$ clamp to impair growth. Alternatively, the $\beta^{\mathrm{C}} / \beta 159$ clamp may be sensitized to the checkpoint function of Pol IV. Regardless of the mechanism(s) by which Pol IV acts to impair growth of the $\beta^{\mathrm{C}}$ expressing strain, the fact that $\beta^{C}$, on its own, is nonfunctional [12], together with our finding that $\beta 159$ cannot support cell viability at $42^{\circ} \mathrm{C}$, even when expressed at an elevated level (Figure $3 \& 4$ ), argues strongly that growth at $42^{\circ} \mathrm{C}$ of the $d n a N 159$ strain relies entirely on the ability of a temperature resistant $\beta^{C} / \beta 159$ heterodimeric clamp to fulfill all essential clamp functions.

\section{Disruption of the Pol IV-clamp rim contact in $\beta^{C}$ fails to alleviate the lethal effect of Pol IV}

The little finger domain of Pol IV (Pol IV $\mathrm{LF}^{\mathrm{LF}}$ ) interacts with the clamp by bridging the dimer interface [14]. In solution, and in the absence of DNA, two Pol IV molecules simultaneously contact a single clamp, with each Pol IV contacting the rim of one protomer, and the cleft of the adjacent clamp protomer (see Figure 2C; [13-15]). As discussed above, the cleft contact is required for stimulation of Pol IV replication [13,30], while the rim contact is required for Pol IV to undergo a switch with a stalled Pol III [13]. We therefore asked whether mutating critical residues in the $\operatorname{rim}$ in $\beta^{C}$, which is adjacent to the cleft in $\beta 159$ (see Figure 2 panels D \& $C)$, alleviated the need to inactivate Pol IV in order for $\beta^{\mathrm{C}}$ to complement temperature sensitivity of the dnaN159 strain. The combination of the E93K and L98K mutations in the clamp was previously demonstrated to severely impair interaction of Pol IV with the rim [13]. A clamp mutant bearing only E93K-L98K substitutions $\left(\beta^{\text {E93K-L98K }}\right)$ was expressed at a level comparable to the wild-type clamp (Figure 3 ). Moreover, the $\beta^{\text {E93K-L98K }}$ mutant clamp fully supported growth of the dnaN159 strain at $42^{\circ} \mathrm{C}$, indicating that these residues were dispensable for essential clamp function(s) in vivo (Figure 4). In striking contrast, $\beta^{\text {C-E93K-L98K }}$ was unable to complement the dnaN159 strain, unless Pol IV was inactivated (Figure 4), despite the fact that the mutant clamp was expressed at physiological levels (Figure 3). Taken together, these results indicate that the ability of Pol IV to impair growth of the $\beta^{C}$-expressing strain is not the result of Pol IV gaining access to the cleft in $\beta 159$ by first binding to the $\operatorname{rim}$ of $\beta^{C}$ in a manner similar to that by which Pol IV switches with a stalled Pol III (see Figure 1B; $[5,13]$ ). It is possible that Pol IV outcompetes Pol III for binding to the cleft of the $\beta 159$ protomer, independently of the rim contact, leading to cell death at $42^{\circ} \mathrm{C}$. Alternatively, binding of multiple Pol IV molecules to some combination of rim and cleft regions of a single $\beta^{C} / \beta 159$ clamp may act to preclude access and/or function of Pol III, possibly via a DNA damage checkpoint response. The affinity of Pol IV for the rim of the clamp is on the order of $\sim 1 \mu \mathrm{M}$ [13], which is intermediate to the SOS-repressed $(\sim 300 \mathrm{nM})$ and SOS-induced levels $(\sim 3,300 \mathrm{nM})$ of Pol IV [5,31], providing support for these models.

\section{$\beta^{C}$ complements the temperature sensitive growth phenotype of the dnaN159 strain via a $\beta^{C} / \beta 159$ heterodimer}

Results discussed above suggest that growth of the dnaN159 strain at $42^{\circ} \mathrm{C}$ relies on a $\beta^{\mathrm{C}} / \beta 159$ heterodimer. We pursued two parallel strategies to test this hypothesis. In our first approach, we sought to purify for subsequent biochemical analysis a recombinant form of the $\beta^{\mathrm{C}} / \beta 159$ heterodimer using an established protocol [12]. Although this recombinant clamp protein was expressed in a soluble form, it became poorly soluble when purified to homogeneity, making it impossible to rigorously establish its purity as a heterodimer, or to accurately measure its ability to support processive DNA replication in vitro (data not shown).

In a parallel strategy, we employed a genetic approach to determine whether a $\beta^{C} / \beta 159$ heterodimer supported growth of the dnaN159 strain. Residues I272 and L273 of $\beta$ map to the dimer interface, and their substitution with alanine in the wild-type clamp leads to its monomerization in vitro [32]. We hypothesized that substitution of these residues in $\beta^{\mathrm{C}}\left(\beta^{\mathrm{C}-\mathrm{I} 272 \mathrm{~A}-\mathrm{L} 273 \mathrm{~A}}\right)$ would destabilize the $\beta^{\mathrm{C}} / \beta 159$ heterodimer in vivo (see Figure $2 \mathrm{D})$, thereby impairing growth at $42^{\circ} \mathrm{C}$. Consistent with our hypothesis, $\beta^{\mathrm{C}-\mathrm{I} 272 \mathrm{~A}-\mathrm{L} 273 \mathrm{~A}}$ was unable to fully complement temperature sensitivity of the dnaN159 strain, irrespective of Pol IV function (Figure 4). Our finding that $\beta^{\text {C-I272A-L273A }}$ was expressed at near physiological levels (Figure 3 ) suggests that its inability to complement temperature sensitivity results from a functional defect. Efforts to clone a $\beta^{\text {I272A-L273A }}$-expressing plasmid to measure its ability to complement the dnaN159 strain as a negative control were unsuccessful, suggesting that 
a monomeric form of the clamp bearing a functional cleft exerts a dominant-negative phenotype in vivo.

As part of this same strategy, we also substituted residue $\mathrm{G} 66$ of $\beta^{C}$ with glutamic acid $\left(\beta^{\mathrm{C}-\mathrm{G} 66 \mathrm{E}}\right)$. Temperature sensitivity of $\beta 159$ requires both the G66E and G174A substitutions [24]. We hypothesized that introduction of the G66E substitution into $\beta^{\mathrm{C}}\left(\beta^{\mathrm{C}-\mathrm{G} 66 \mathrm{E}}\right)$ would effectively mimic its effect in $\beta 159$, rendering both the $\beta^{\mathrm{C}-\mathrm{G} 66 \mathrm{E}}$ mutant, as well as the $\beta^{\mathrm{C}-\mathrm{G} 66 \mathrm{E}} / \beta 159$ heterodimer thermolabile. Consistent with this hypothesis, $\beta^{\mathrm{C}-\mathrm{G} 66 \mathrm{E}}$ was unable to fully complement growth of the dnaN159 strain (Figure 4). Based on Western blotting (Figure 3), $\beta^{\mathrm{C}-\mathrm{G} 66 \mathrm{E}}$ was expressed at physiological levels (note that the G66E substitution slows mobility of clamp in SDS-PAGE [24]). Thus, taken together, results discussed above suggest that a $\beta^{\mathrm{C}} / \beta 159$ heterodimer supports growth of the dnaN159 strain at $42^{\circ} \mathrm{C}$, suggesting that a single cleft in the clamp is capable of supporting all essential clamp functions in vivo.

\section{$\beta^{C}$ supports DNA damage-induced mutagenesis in the dnaN159 strain}

Our finding that a $\beta^{\mathrm{C}} / \beta 159$ heterodimer supports growth of the dnaN159 strain at $42^{\circ} \mathrm{C}$ provided us with a tractable system to determine whether a clamp bearing a single functional cleft was capable of coordinating the actions of Pol III and TLS Pols following DNA damage. Since growth of the $\beta^{\mathrm{C}}$ strain at $42^{\circ} \mathrm{C}$ required that the gene for Pol IV be deleted, we were unable to analyze Pol IV function. However, we were able to analyze Pol $\mathrm{V}(u m u D C)$ function. For this, we cultured the dnaN159 $\Delta(\operatorname{din} B-y a f N):: k a n$ strain expressing either the wild-type or $\beta^{\mathrm{C}}$ clamp from a plasmid in liquid broth at $42^{\circ} \mathrm{C}$. Exponential phase cultures were either irradiated with $254 \mathrm{~nm}$ ultraviolet light (UV), or mock irradiated, and appropriate dilutions of each culture were plated to determine the frequency of spontaneous and UVinduced Rif ${ }^{\mathrm{R}}$. Both the $\beta^{+}\left(4.4 \pm 1.7 \times 10^{-9}\right)$ and $\beta^{\mathrm{C}}(4.8$ $\left.\pm 1.7 \times 10^{-9}\right)$ strains displayed spontaneous mutation frequencies comparable to those reported for similar E. coli strains $[29,33]$. DNA mismatch repair (MMR) function is required for correcting replication errors, ensuring a low (e.g., normal) spontaneous mutation frequency [1]. Inasmuch as interaction of both MutS and MutL with the clamp is required for MMR in vivo [34], these findings suggest that a single cleft in the clamp is capable of supporting MMR, and coordinating it with replication. In contrast to their spontaneous mutation frequencies, the frequency of UV-induced mutagenesis was $\sim 2.5$-fold higher in the $\beta^{C}$-expressing strain compared to the wild-type control (Figure 5A), suggesting that the $\beta^{C} / \beta 159$ heterodimer may be impaired for proper coordination of Pol III and Pol V, resulting in more frequent access of Pol V to the replication fork
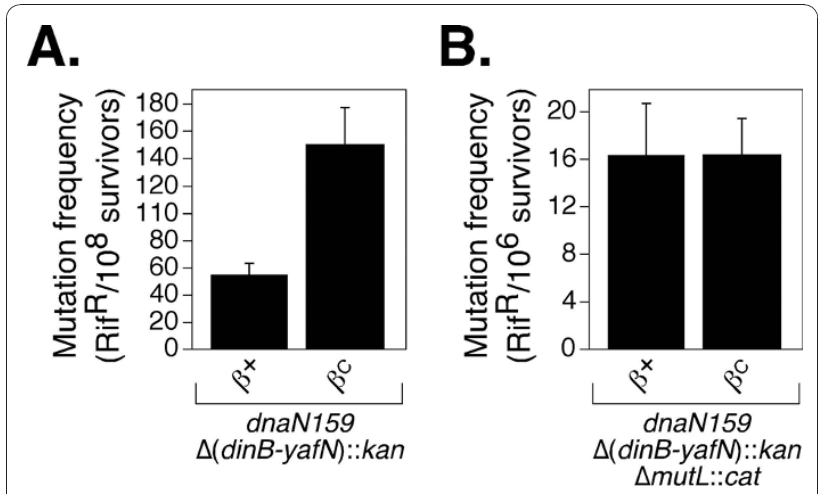

Figure 5 Ability of $\beta^{C}$ to support Pol V-dependent UV-induced mutagenesis in vivo. UV-induced mutagenesis was measured using isogenic (A) mutL ${ }^{+}$(MS125) and (B) $\Delta$ mutL::cat (MS148) dnaN159 $\triangle($ dinB-yafN)::kan strains expressing physiological levels of either $\beta^{+}$(pJD100) or $\beta^{C}$ (pMDS110), as described in 'METHODS. Results shown are the average of at least 4 determinations. Error bars represent the standard deviation.

following UV irradiation. Although we cannot rule out the possibility that partially functional $\beta 159$ homodimers persist in the dnaN159 strain, we previously determined that $\beta 159$ homodimers were impaired for Pol V-dependent UV mutagenesis at $37^{\circ} \mathrm{C}[24,27]$. Taken together, these results argue that the $\beta^{C} / \beta 159$ heterodimer supports Pol V-dependent mutagenesis at $42^{\circ} \mathrm{C}$.

In addition to correcting replication errors catalyzed by Pol III, MMR also acts to correct errors catalyzed by Pol V during TLS, including misinsertions opposite thymine-thymine dimers [35], as well misinsertions opposite undamaged bases adjacent to UV adducts which, if left uncorrected, result in 'hitchhiker' mutations [36]. Since the mechanism by which MMR catalyzes repair during TLS may differ from that during Pol III replication, we measured the frequency of UV-induced mutagenesis in the MMR-deficient $\Delta$ mutL::cat strain background (MS148). As summarized in Figure 5B, frequencies of UV-induced mutagenesis in the $\beta^{+}$and $\beta^{C}$ strains were comparable, suggesting that $\beta^{\mathrm{C}} / \beta 159$ was able to properly manage the actions of Pol III and Pol V in vivo. The spontaneous mutation frequency of the $\beta^{C}$ strain was elevated $\sim 2.5$-fold relative to the $\beta^{+}$strain $\left(6.9 \times 10^{-6}\right.$ compared to $\left.2.5 \times 10^{-6}\right)$, suggesting that one or more aspects of DNA replication and/or accurate repair were modestly affected by the $\beta^{C} / \beta 159$ clamp. Interestingly, a different dnaN159 $\Delta$ mutL::cat strain displayed a similarly elevated spontaneous mutation frequency at the permissive temperature of $30^{\circ} \mathrm{C}$ [33], suggesting that this phenotype was due to the $\beta 159$ protomer. Taken together, results discussed above suggest that although a single cleft in the $\beta$ clamp is sufficient to coordinate the actions of Pol III and Pol V in vivo 
(see Figure 1B), both clefts are required for proper MMR function during TLS.

\section{Conclusions}

Results summarized in this report indicate that $\beta^{C}$ complements both the temperature sensitivity and Pol Vdependent UV-induced mutator defect of the dnaN159 strain, provided that Pol IV is inactivated (Figure $4 \& 5$ ). Taken together, these findings suggest that a single cleft in the clamp is sufficient to support all essential clamp functions in vivo, and provide additional support for our model that a single cleft is sufficient to coordinately manage the actions of multiple clamp partners on DNA (see Figure 1B; $[5,13])$. It is presently unclear why Pol IV function prevents $\beta^{C}$ from complementing the dnaN159 strain. It is possible that Pol IV associates with surfaces in addition to the rim and cleft to somehow impair growth, possibly as part of a DNA damage checkpoint control (see Figure 1; $[18,19]$ ). Alternatively, Pol IV may simply out compete Pol III for access to the $\beta^{C} / \beta 159$ clamp on leading and/or lagging strand. Other scenarios are also possible. Regardless of the mechanism(s), the fact that Pol IV impairs growth of the $\beta^{C}$ strain suggests that a single cleft on the clamp is also sufficient to support Pol IV function(s) in vivo. An obvious limitation of the method used to generate heterodimeric clamps in vivo is the possibility that partially functional $\beta 159$ homodimers persist. Rational design of novel mutant clamp proteins bearing site-specific mutations at the dimer interface that impair homodimerization while simultaneously enabling dimerization in trans (e.g., heterodimers) would circumvent this issue, and would provide a powerful approach for dissecting mechanisms by which the clamp manages events at a replication fork in vivo. Finally, although not addressed in this study, proteins in addition to clamp, as well as the DNA template itself contribute to Pol switching (reviewed in [5]). Defining the respective contributions of these non-clamp factors in this multifaceted process will be made simpler once the roles played by clamp are defined in molecular terms.

\section{Methods}

\section{Bacteriological techniques}

Isogenic E. coli strains and plasmid DNAs utilized in this work are described in Table 1 . Strain DH5 $\alpha$ was used as host for cloning plasmids. Strains MS146, MS147, and MS148 were constructed by generalized transduction using P1vir [37]. The presence of the $\Delta$ (araD-polB):: $\Omega$ allele was confirmed by diagnostic PCR, as described previously [26]. Strains were routinely cultured in Luria-Bertani medium (LB; $10 \mathrm{~g} / \mathrm{l}$ tryptone, $5 \mathrm{~g} / \mathrm{l}$ yeast extract, $10 \mathrm{~g} / \mathrm{l}$ sodium chloride; [37]). Strains bearing plasmids were grown in medium containing ampicillin (Amp) at a final concentration of $150 \mu \mathrm{g} / \mathrm{ml}$.
When noted, IPTG was added at a final concentration of $50 \mu \mathrm{M}$ to induce expression of physiological levels of the plasmid-encoded clamp protein [27]. At least two independent plasmid clones were separately transformed into each strain, and at least two independent transformants of each plasmid/strain were used for each experiment.

\section{Site-directed mutagenesis}

Site-directed mutagenesis was performed using the Quick-Change mutagenesis kit (Stratagene). Primers employed in mutagenesis were synthesized by SigmaGenosys, and their sequences are listed in Table 1. Plasmid pJD100 $\left(d n a N^{+}\right)$, or pMDS110 $\left(d n a N^{C}\right.$; see Table 1$)$, served as template for PCR reactions. PCR amplification was for 18 cycles of $95^{\circ} \mathrm{C}$ for $30 \mathrm{~s}, 55^{\circ} \mathrm{C}$ for $1 \mathrm{~min}, 68^{\circ} \mathrm{C}$ for $12 \mathrm{~min}$. After PCR, reactions $(50 \mu \mathrm{l})$ were treated with $D p n \mathrm{I}(10 \mathrm{U})$ for $1 \mathrm{~h}$ to digest the parental template DNA prior to transforming it into chemically competent DH5 $\alpha$. Transformants were selected by virtue of their resistance to Amp. Plasmid clones were individually purified using the Qiagen Spin Prep kit, and screened by restriction analysis prior to determining the nucleotide sequence of two independent clones for each (Roswell Park Cancer Center Biopolymer Facility).

\section{Western blotting}

Western blot analysis was performed as described previously [27] using cultures of MS101 bearing the indicated plasmids grown at $30^{\circ} \mathrm{C}$ (the permissive temperature for the pWSK29 [control] and pJD109 [dnaN159] transformants) in LB medium supplemented with Amp and IPTG. When cells reached exponential phase $\left(\mathrm{OD}_{595} \sim 0.5\right)$, a volume of culture equivalent to 1 $\mathrm{ml}$ of $\mathrm{OD}_{595}=1.0$ was harvested by centrifugation. Cell pellets were washed once with $0.8 \%$ saline prior to being resuspended in SDS-PAGE loading buffer (50 mM Tris$\mathrm{HCl}$ [pH 6.8], $25 \mathrm{mM}$ dithiothreitol, 2\% SDS, $0.2 \%$ bromophenyl blue, and $10 \%$ glycerol) at a density of $\sim 10^{7}$ cells $/ \mu \mathrm{l}$. Ten $\mu \mathrm{l}\left(\sim 10^{8}\right.$ cells $)$ of each sample was electrophoresed through a $12 \%$ SDS-PAGE, transferred to PVDF, blotted with rabbit polyclonal anti- $\beta$ antibodies, and immuno-reactive material was detected using the Super Signal Western Dura Extended Chemiluminescence substrate (Pierce) as described previously [27]. Based on quantitative Western blot analysis, strain MS101 (dnaN159) expressed $281 \pm 90$ clamps/cell (as dimer), while MS101 bearing pJD100 $\left(\beta^{+}\right)$expressed $1,144 \pm 532$ clamps/cell [27].

\section{UV-induced mutagenesis}

UV-induced mutagenesis was performed as described previously [27]. Briefly, cultures were grown to exponential phase $\left(\mathrm{OD}_{595} \sim 0.5\right)$ at $42^{\circ} \mathrm{C}$ in liquid $\mathrm{LB}$ medium 
Table 1 E. coli strains, plasmid DNAs, and synthetic oligonucleotides used in this study

\begin{tabular}{|c|c|c|}
\hline \multicolumn{3}{|c|}{ E. coli strains: } \\
\hline Strain & Relevant genotype & Source \\
\hline $\mathrm{DH} 5 \alpha$ & endA1 hsdR17 $\left(r_{\mathrm{K}}^{-} \mathrm{m}_{\mathrm{K}}{ }^{+}\right)$gInV44 thi-1 recA1 gyrA96 relA1 deoR nupG $\Delta($ lacZYA-argF)U169 ( $\phi 80 d l a c Z \Delta M 15)$ & Invitrogen \\
\hline MS101 & $\begin{array}{l}\text { thr-1 araD139 } \Delta(\text { gpt-proA)62 lacY1 tsx-33 supE44 galK2 hisG4(Oc) rpsL31 xyl-5 mtl-1 argE3(Oc) thi-1 sulA211 dnaN159(Ts) } \\
\text { thaA300::Tn10 }\end{array}$ & {$[26]$} \\
\hline MS146 & MS101 with $\Delta(a r a D-p o / B):: \Omega$ & This work \\
\hline MS125 & MS101 with $\Delta($ dinB-yafN)::kan & [28] \\
\hline MS147 & MS101 with $\triangle$ umuDC596::ermGT & This work \\
\hline MS148 & MS101 with $\triangle($ dinB-yafN)::kan $\triangle$ mutl::cat & This work \\
\hline \multicolumn{3}{|c|}{ Plasmid DNAs: } \\
\hline Plasmid & Relevant characteristics & Source \\
\hline pWSK29 & Amp ${ }^{R}$; pSC101 origin; low copy number general cloning vector & [39] \\
\hline pJD100 & $\mathrm{Amp}^{\mathrm{R}}$; pWSK29 containing the $d n a N^{+}\left(\beta^{+}\right)$gene under the control of its native promoters & [26] \\
\hline pJD109 & $\mathrm{Amp}^{\mathrm{R}} ;$ pJD100 bearing dnaN159 (G66E and G174A substitutions; $\left.\beta 159\right)$ & [27] \\
\hline pMDS110 & Amp $^{R} ;$ pJD100 bearing dnaN lacking residues 362-366 $\left(d n a N^{C} ; \beta^{C}\right)$ & This work \\
\hline pMDS111 & Amp $^{R} ;$ pJD100 bearing dnaN lacking residues $362-366$ and containing a G66E substitution (dnaN ${ }^{C-G 66 E} ; \beta^{C-G 66 E}$ ) & This work \\
\hline pMDS112 & 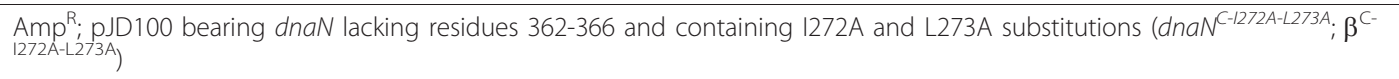 & This work \\
\hline pMDS113 & Amp $^{\text {R; }}$ pJD100 bearing dnaN containing E93K and L98K substitutions $\left(\right.$ dnaN $\left.^{\text {E93K-L98K }} ; \beta^{\text {E93K-L98K }}\right)$ & This work \\
\hline pMDS114 & 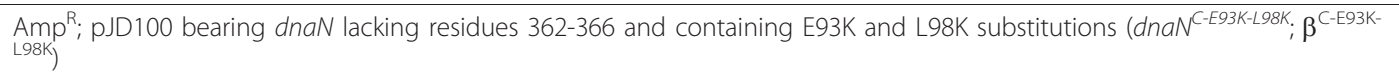 & This work \\
\hline \multicolumn{3}{|c|}{ Oligonucleotides: } \\
\hline Name & Nucleotide sequence $\left(5^{\prime} \rightarrow 3^{\prime}\right)$ & \\
\hline$\Delta 362-366-\top$ & GGCTTATGTTGTCTAATGAATGAGACTG & \\
\hline$\Delta 362-366-B$ & CAGTCTCATTCATTAGACAACATAAGCC & \\
\hline G66E-T & CAGCCACACGAGCCAGAAGCGACGACCGTTCCGG & \\
\hline G66E-B & CCGGAACGGTCGTCGCTTCTGGCTCGTGTGGCTG & \\
\hline $\begin{array}{l}\text { I272A-L273A- } \\
\text { T }\end{array}$ & GTTGCTCGCGCGGCGGCTGCCTCTAACGAGAAATTCCG & \\
\hline $\begin{array}{l}\text { I272A-L273A- } \\
\text { B }\end{array}$ & CGGAATTTCTCGTTAGAGGCAGCCGCCGCGCGAGCAAAC & \\
\hline E93K-L98K-T & CGTGCAGCTGAAAGGTGAACGGATGAAAGTACGCTCCGG & \\
\hline E93K-L98K-B & CCGGAGCGTACTTCATCCGTTCACCTTTCAGCTGCACG & \\
\hline
\end{tabular}

supplemented with Amp and IPTG, at which point cells were harvested by centrifugation, washed twice with $0.8 \%$ saline before being resuspended in saline, and either UV irradiated $\left(25 \mathrm{~J} / \mathrm{m}^{2}\right)$ using a germicidal lamp (254 nM, GE Healthcare) or mock irradiated. Following irradiation, cells were allowed to recover overnight at $42^{\circ} \mathrm{C}$ in liquid LB medium supplemented with Amp prior to plating appropriate dilutions onto LB agar plates containing Amp with or without $100 \mu \mathrm{g} / \mathrm{ml}$ Rif. Mutation frequency was calculated by dividing the number of $\mathrm{Rif}^{\mathrm{R}} \mathrm{CFU} / \mathrm{ml}$ by the total number of viable cells/ $\mathrm{ml}$. UV-induced mutation frequency is expressed as the frequency of Rif ${ }^{R}$ observed following exposure to UV minus the spontaneous mutation frequency observed for the mock irradiated control.
List of Abbreviations

Pol: DNA polymerase; TLS: translesion DNA synthesis; CBM: clamp-binding motif; UV: ultraviolet light; MMR: mismatch repair; LB: Luria-Bertani; Amp: ampicillin; $A m p^{R}$ : ampicillin resistance; Rif: rifampicin; Rif $f^{R}$ : rifampicin resistant.

\section{Acknowledgements}

This work was supported by NIH grant GM066094 to MDS. The authors thank the members of our lab for helpful discussions, as well as both anonymous reviewers for their insightful comments.

\section{Author details}

'Department of Biochemistry, and Witebsky Center for Microbial Pathogenesis and Immunology, School of Medicine and Biomedical Sciences, University at Buffalo, State University of New York, 3435 Main Street, 140 Farber Hall, Buffalo, NY 14214, USA. ²Department of Biochemistry, School of Medicine and Biomedical Sciences, University at Buffalo, State University of New York, 3435 Main Street, 140 Farber Hall, Buffalo, NY 14214, USA. ${ }^{3}$ Current Address: Department of Immunology, Roswell Park Cancer Institute, Buffalo, NY 14263, USA. 


\section{Authors' contributions}

MDS conceived the project, designed the experiments, and wrote the paper. All three authors contributed to performing the experiments, and each read and approved the final manuscript.

Received: 7 October 2010 Accepted: 29 December 2010

Published: 29 December 2010

\section{References}

1. Friedberg EC, Walker GC, Siede W, Wood RD, Schultz RA, Ellenberger T: DNA repair and mutagenesis. Washington, D.C.: ASM Press; 22006.

2. Howard-Flanders P: Repair by genetic recombination in bacteria: overview. Basic Life Sci 1975, 265-274.

3. Waters LS, Minesinger BK, Wiltrout ME, D'Souza S, Woodruff RV, Walker GC: Eukaryotic translesion polymerases and their roles and regulation in DNA damage tolerance. Microbiol Mol Biol Rev 2009, 73(1):134-154.

4. Friedberg EC, Lehmann AR, Fuchs RP: Trading places: how do DNA polymerases switch during translesion DNA synthesis? Mol Cell 2005, 18(5):499-505.

5. Sutton MD: Coordinating DNA polymerase traffic during high and low fidelity synthesis. Biochim Biophys Acta 2010, 1804(5):1167-1179.

6. Moldovan GL, Pfander B, Jentsch S: PCNA, the maestro of the replication fork. Cell 2007, 129(4):665-679.

7. Bloom LB: Dynamics of loading the Escherichia coli DNA polymerase processivity clamp. Crit Rev Biochem Mol Biol 2006, 41(3):179-208.

8. Dalrymple BP, Kongsuwan K, Wijffels G, Dixon NE, Jennings PA: A universal protein-protein interaction motif in the eubacterial DNA replication and repair systems. Proc Natl Acad Sci USA 2001, 98(20):11627-11632.

9. Pages V, Fuchs RP: How DNA lesions are turned into mutations within cells? Oncogene 2002, 21(58):8957-8966.

10. Indiani C, Mclnerney P, Georgescu R, Goodman MF, O'Donnell M: A slidingclamp toolbelt binds high- and low-fidelity DNA polymerases simultaneously. Mol Cell 2005, 19(6):805-815.

11. Duzen JM, Walker GC, Sutton MD: Identification of specific amino acid residues in the $E$. coli beta processivity clamp involved in interactions with DNA polymerase III, UmuD and UmuD'. DNA Repair (Amst) 2004, 3(3):301-312.

12. Scouten Ponticelli SK, Duzen JM, Sutton MD: Contributions of the individual hydrophobic clefts of the Escherichia coli beta sliding clamp to clamp loading, DNA replication and clamp recycling. Nucleic Acids Res 2009, 37(9):2796-2809.

13. Heltzel JM, Maul RW, Scouten Ponticelli SK, Sutton MD: A model for DNA polymerase switching involving a single cleft and the rim of the sliding clamp. Proc Natl Acad Sci USA 2009, 106(31):12664-12669.

14. Bunting KA, Roe SM, Pearl LH: Structural basis for recruitment of translesion DNA polymerase Pol IV/DinB to the beta-clamp. EMBO J 2003, 22(21):5883-5892.

15. Wagner J, Etienne H, Fuchs RP, Cordonnier A, Burnouf D: Distinct betaclamp interactions govern the activities of the Y family Pol IV DNA polymerase. Mol Microbiol 2009, 74(5):1143-1151.

16. Beuning PJ, Sawicka D, Barsky D, Walker GC: Two processivity clamp interactions differentially alter the dual activities of UmuC. Mol Microbiol 2006, 59(2):460-474

17. Opperman T, Murli S, Smith BT, Walker GC: A model for a umuDCdependent prokaryotic DNA damage checkpoint. Proc Natl Acad Sci USA 1999, 96(16):9218-9223.

18. Uchida K, Furukohri A, Shinozaki Y, Mori T, Ogawara D, Kanaya S, Nohmi T, Maki H, Akiyama M: Overproduction of Escherichia coli DNA polymerase DinB (Pol IV) inhibits replication fork progression and is lethal. $\mathrm{Mol}$ Microbiol 2008, 70(3):608-622.

19. Indiani C, Langston LD, Yurieva O, Goodman MF, O'Donnell M: Inaugural Article: Translesion DNA polymerases remodel the replisome and alter the speed of the replicative helicase. Proc Natl Acad Sci USA 2009.

20. Sutton MD, Opperman T, Walker GC: The Escherichia coli SOS mutagenesis proteins UmuD and UmuD' interact physically with the replicative DNA polymerase. Proc Natl Acad Sci USA 1999, 96(22):12373-12378.

21. Heltzel JMH, Scouten Ponticelli SK, Sanders LH, Duzen JM, Cody V, Pace J, Snell EH, Sutton MD: Sliding clamp-DNA interactions are required for viability and contribute to DNA polymerase management in Escherichia coli. Journal of Molecular Biology 2009, 387:74-91.
22. Georgescu RE, Kim SS, Yurieva O, Kuriyan J, Kong XP, O'Donnell M: Structure of a sliding clamp on DNA. Cell 2008, 132(1):43-54.

23. Bloom LB: Loading clamps for DNA replication and repair. DNA Repair (Amst) 2009, 8(5):570-578.

24. Maul RW, Ponticelli SK, Duzen JM, Sutton MD: Differential binding of Escherichia coli DNA polymerases to the beta-sliding clamp. Mol Microbiol 2007, 65(3):811-827.

25. Kawakami H, Iwura T, Takata M, Sekimizu K, Hiraga S, Katayama T: Arrest of cell division and nucleoid partition by genetic alterations in the sliding clamp of the replicase and in DnaA. Mol Genet Genomics 2001, 266(2):167-179.

26. Sutton MD: The Escherichia coli dnaN159 mutant displays altered DNA polymerase usage and chronic SOS induction. J Bacteriol 2004, 186(20):6738-6748.

27. Sutton MD, Duzen JM, Maul RW: Mutant forms of the Escherichia coli beta sliding clamp that distinguish between its roles in replication and DNA polymerase V-dependent translesion DNA synthesis. Mol Microbiol 2005, 55(6):1751-1766

28. Sutton MD, Duzen JM: Specific amino acid residues in the beta sliding clamp establish a DNA polymerase usage hierarchy in Escherichia coli. DNA Repair (Amst) 2006, 5(3):312-323.

29. Maul RW, Sutton MD: Roles of the Escherichia coli RecA protein and the global SOS response in effecting DNA polymerase selection in vivo. $J$ Bacteriol 2005, 187(22):7607-7618

30. Lenne-Samuel N, Wagner J, Etienne H, Fuchs RP: The processivity factor beta controls DNA polymerase IV traffic during spontaneous mutagenesis and translesion synthesis in vivo. EMBO Rep 2002, 3(1):45-49.

31. Kim SR, Matsui K, Yamada M, Gruz P, Nohmi T: Roles of chromosomal and episomal $\operatorname{din} B$ genes encoding DNA pol IV in targeted and untargeted mutagenesis in Escherichia coli. Mol Genet Genomics 2001, 266(2):207-215.

32. Stewart J, Hingorani MM, Kelman Z, O'Donnell M: Mechanism of beta clamp opening by the delta subunit of Escherichia coli DNA polymerase III holoenzyme. J Biol Chem 2001, 276(22):19182-19189.

33. Maul RW, Sanders LH, Lim JB, Benitez R, Sutton MD: Role of Escherichia col DNA polymerase I in conferring viability upon the dnaN159 mutant strain. J Bacterio/ 2007, 189(13):4688-4695.

34. Lopez de Saro FJ, Marinus MG, Modrich P, O'Donnell M: The beta sliding clamp binds to multiple sites within MutL and MutS. J Biol Chem 2006, 281(20):14340-14349.

35. Hoffman PD, Wang H, Lawrence CW, Iwai S, Hanaoka F, Hays JB: Binding of MutS mismatch repair protein to DNA containing UV photoproducts, "mismatched" opposite Watson-Crick and novel nucleotides, in different DNA sequence contexts. DNA Repair (Amst) 2005, 4(9):983-993.

36. Caillet-Fauquet $\mathrm{P}$, Maenhaut-Michel $\mathrm{G}$, Radman M: SOS mutator effect in $E$. coli mutants deficient in mismatch correction. EMBO J 1984, 3(4):707-712.

37. Miller JH: A short course in bacterial genetics: a laboratory manual and handbook for Escherichia coli and related bacteria. Cold Spring Harbor Press; 1999.

38. Furukohri A, Goodman MF, Maki H: A dynamic polymerase exchange with Escherichia coli DNA polymerase IV replacing DNA polymerase III on the sliding clamp. J Biol Chem 2008, 283(17):11260-11269.

39. Wang RF, Kushner SR: Construction of versatile low-copy-number vectors for cloning, sequencing and gene expression in Escherichia coli. Gene 1991, 100:195-199.

doi:10.1186/1471-2199-11-102

Cite this article as: Sutton et al:: A single hydrophobic cleft in the Escherichia coli processivity clamp is sufficient to support cell viability and DNA damage-induced mutagenesis in vivo. BMC Molecular Biology 2010 11:102. 